\title{
Rare type of bladder cancer: Malign fibrous histiocytoma
}

\author{
Orcun Celik, Hakan Turk, Salih Budak, Yusuf Ozlem Ilbey \\ Tepecik Educational and Research Hospital, Urology Clinic, Izmir, Turkey
}

\begin{abstract}
Summary Malignant fibrous histocytoma (MFH) is the most common soft tissue sarco$m a$ in adults. Urinary tract is a very rare location for MFH. Involvement of the bladder is more common in males and at the 6th decade of life.

A case of MFH of the bladder with poor prognosis is presented. Prognostic factors for MFH are tumor grade, amount of invasion, age, tumor size, and histological type. Survival rate is very low and 3-year disease specific survival is approximately $40 \%$.
\end{abstract}

KEY WORDS: Malignant fibrous histocytoma; Bladder; Tumour.

Submitted 28 April 2014; Accepted 31 May 2014

\section{INTRODUCTION}

Malignant fibrous histocytoma (MFH) is a mesenchimal tumor, which was described by O'Brien and Stout in 1964 (1). MFH is an aggressive tumor with fusiform cells that is the most common soft tissue sarcoma in adults (2). Urinary tract, especially bladder is a very rare location for MFH with only 29 previously reported cases.

Involvement of the bladder is more common in males and at the 6th decade of life. Clinical presentation is similar to other bladder tumors. In the bladder this mesenchimal tumor and its variants should be distinguished with immunohistochemical methods from sarcomatoid carcinoma, inflammatory myofibroblastic tumor and leiomyosarcoma (3). MFH spreads fast and is generally metastatic. Size, depth and histologic features of the tumor are important factors for metastasis (4). Because of its rapid local and distant metastatic character, radical cystectomy, lymph node dissection and adjuvant radiotherapy are the first line treatments $(5,6)$. Despite this treatment, 3 -year survival is approximately $40 \%$. This is probably due to its low frequency and lack of consensus on treatment. In the current article, we aim to review the relevant literature in the light of a case.

\section{Case report}

A 57-year old man applied to our clinic with hematuria for one month. He had a trauma history that occurred 20 years before and he was using TAK. Following the initial examination and investigation, we detected a bladder tumor and transurethral resection (TUR) was performed. Pathological examination showed a muscle-invasive tumour with the characteristics of a malignant fibrous histocytoma. Toraco-abdominal tomography, hemogram, and biochemical tests were planned for staging. Hydronephrosis in the left kidney and high calcium levels $(15 \mathrm{mg} / \mathrm{dl})$ were detected. Because of the high calcium levels, we performed a bone scintigraphy and detected suspicious areas in ribs and femur head probably indicating the presence of bone metastasis. All these lesions were confirmed with magnetic resonance imaging (MRI). High calcium level could not be lowered with medical treatment. Therefore, patient underwent haemodialysis, but calcium levels remained high even after dialysis. After patient and patient's relatives request, patient was discharged and died one month later.

\section{Discussion}

MFH as a common soft tissue sarcoma in adults that constitutes $10-21 \%$ of all sarcomas. It is observed more commonly in lower extremities (50\%), upper extremities (20\%) and retroperitoneal space (15\%). It is rare in the urinary tract and if seen, it is located mostly in the kidneys. Non-epithelial tumors of the bladder consist of $2 \%$ of all bladder tumors and mesenchimal tumors of the bladder consist of $0.23-0.67 \%$ of all bladder tumors (7). MFH in the bladder is more common in males (4:1) and at the $6^{\text {th }}$ decade of life and commonly presents with macroscopic hematuria. Some experts suggested that it is related to radiotherapy and chemotherapy and it often cooccurs (approximately 13\%) with other tumors (leukemia, Hodgkin lymphoma, multiple myeloma) $(5,8)$. MFH in bladder presents as a large-sized tumor, with diameter of approximately $6.4 \mathrm{~cm}(1-15 \mathrm{~cm})$. In our case, the diameter of tumor was $10 \mathrm{~cm}$ and extracted material was $30 \mathrm{cc}$. At diagnosis, $16 \%$ of patients are T2, $72 \%$ of patients T3 and $14 \%$ T4 (9). Disease specific survival is $47.8 \%$ at 1 year and $31.9 \%$ at 2 years (9). As it is an aggressive and rare type of tumor and there is limited number of studies, treatment is not very successful. There are mainly four morphological types (3): 1) inflammatory type (36\%), 2) storiform-fascicular type (40\%), 3) pleomorphic type (13\%) and 4) myxoid type (9\%) (10). At immunohisto- 
chemical evaluation, it is vimentin, alpha-1 antichymotrypsin and factor 13A positive. In our case, the tumor was positive for vimentin and CD68.

\section{ConcLusion}

MFH in the bladder is a rare tumor and there are approximately 29 cases reported in the literature. It presents with macroscopic hematuria and is more common in men and in the $6^{\text {th }}$ decade of life. The tumor is generally large and locally advanced or metastatic like in our case. Survival rate is low and there is no consensus on treatment strategies. Histochemical evaluation is needed to distinguish MFH that has four morphological variants from similar tumors. Prognostic factors for MFH are tumor grade, amount of invasion, age, tumor size, and histological type. Because of its aggressive characteristics, local and distant metastases are likely. Therefore, cystectomy and lymph node dissection and further adjuvant radiotherapy to prevent local recurrence and adriamicin chemotherapy for distant metastasis can be used. However, there is no consensus on treatment strategies (11). Survival rate is very low and 3-year disease specific survival is approximately $40 \%$ (9). Further studies are needed in this topic.

\section{REFERENCES}

1. Kearney MM, Oule EH, Ivins JC. Malignant fibrous histiocytoma. A retrospective study of 167 cases. Cancer. 1980; 45;167-78
2. Weiss SW, Enzinger FM. Malignant fibrous histiocytoma: an analysis of 200 cases. Cancer. 1978; 41:2250.

3. Lott S, Lopez Beltran A, Montironi R, et al. Soft tissue tumors of the urinary bladder. Part II: Malignant neoplasms. Human Pathology. 2007; 38:963-77.

4. Brennan M, Singer S, Maki RG, et al. Sarcomas of the soft tissues and bone 7 th ed. Philadelphia, Lippincott Williams \& Wilkins. 2005; 1581-1631.

5. Beltran A, Pacelli A, Rothenberg HK, et al. Carcinosarcoma and sarcomatoid carcinoma of the bladder: Clinicopathological study of 41 cases. J Urol. 1998; 159:1497-503.

6. Froehner M, Manseck A, Haase M, et al. Locally recurrent malignant fibrous histiocytoma: A rare and aggressive genitourinary malignancy. Urologia Internationalis. 1999; 62:164-70.

7. Kunze E, Theuring F, Kruger G. Primary mesenchymal tumors of the urinary bladder. A histological and immunohistochemical study of 30 cases. Pathol Res Pract. 1994; 190:311-32.

8. Helpap B. Nonepithelial neoplasms of the urinary bladder, Virchows Arch. 2001; 439:497-503.

9. Gunia S, May M, Koch S, et al. Is Radical Oncosurgery Justified for the Treatment of Primary Malignant Fibrous Histiocytoma of the Urinary Bladder? Report of Two Cases and Analyses of DiseaseSpecific Survival Rates Based on a Review of the Literature Urol Int. 2011; 86:261-268.

10. Martín LP, Vilar DG, Sanz MB, et al. Malignant fibrous histiocytoma of the bladder. A literature review Actas Urol Esp. 2010; 34:378-85.

11. Oesterling JE, Epstein JI, Brendler CB. Myxoid malignant fibrous histiocytoma of the bladder. Cancer. 1990; 66:1836-1842.

\section{Correspondence}

Orcun Celik, MD (Corresponding Author)

orcuncelik82@hotmail.com

Hakan TURK, MD

Salih Budak, MD

Yusuf Ozlem Ilbey, MD

Tepecik Educational and Research Hospital, Urology Clinic

35140 Izmir, Turkey 